\title{
Concepções de justiça escolar em documentos do PNUD e da UNESCO'
}

\author{
Maria José de Rezende 2 \\ ORCID: 0000-0002-3426-910X
}

\section{Resumo}

Ao lerem-se os documentos do PNUD e UNESCO, que compõem o sistema das Nações Unidas, percebem-se modelos prospectivos - sobre justiça, escola justa, justiça escolar - que têm conectividade com uma vasta literatura acadêmica sobre educação e direitos humanos e educação e justiça social. Esta é uma pesquisa documental que busca averiguar de que modo os documentos intitulados Relatórios de Monitoramento da Educação para Todos da UNESCO (REPTs) e Relatórios do Desenvolvimento Humano (RDHs) procuram, no limiar do século XXI, atestar a eficácia da educação e da escola como promotoras da inclusão social, econômica e política dos indivíduos. As suas prescrições são feitas aos Estados, às organizações da sociedade civil e às lideranças políticas comprometidas com uma educação mais justa e democrática. Ressaltou-se, no decorrer da análise, que os diagnósticos e as prescrições, presentes nos respectivos documentos, por visarem a alcançar espaços territoriais e contextos sociais e políticos expressivamente amplos não se atêm, suficientemente, aos processos conflitivos que podem, em condições sociais, políticas e educacionais específicas, impossibilitar a ampliação da justiça, de modo geral, e da justiça escolar, de modo particular. Em razão da diversificada natureza dos prognósticos presentes nesses relatórios, não é possível, aos seus formuladores, atentar para as singularidades das diversas sociedades como um espaço de inúmeros conflitos que tendem a ampliar as difıculdades de avanços substantivos rumo a uma crescente justiça escolar.

\section{Palavras-chave}

Direito à educação - Direitos humanos - Escola justa - Justiça social.

1- PNUD (Programa das Nações Unidas para o Desenvolvimento). UNESCO (Organização das Nações Unidas para a Educação e a Cultura). 2- Universidade Estadual de Londrina (UEL); Londrina, Paraná. Brasil. Contato: mjderezende@gmail.com 


\section{School justice concepts in UNDP and UNESCO documents*}

\section{Abstract}

By reading the UNDP and UNESCO documents, which make up the United Nations system, it is possible to see prospective models - concerning justice, just school, school justice which are connected to a vast academic literature on education and human rights as well as education and social justice. This is a documentary research which aims to find out in which ways the documents entitled Education for All Global Monitoring Reports (REPTs) of UNESCO and Human Development Reports (RDHs) seek, at the threshold of the 21st century, to certify the effectiveness of education and school as promoters of social, economic and political inclusion of individuals. Their prescriptions are made to States, civil society organizations and political leaders committed to a more just and democratic education. It was emphasized, in the course of the analysis, that the diagnoses and prescriptions, present in the respective documents, as their goal is to reach expressively broad territorial spaces as well as social and political contexts, are not sufficiently concerned with the conflicting processes that can, under specific social, educational and political conditions, make it impossible to expand justice, in general, and school justice, in particular. Due to the diverse nature of the prognoses present in these reports, it is not possible for their formulators to pay attention to the singularities of different societies as a space of innumerable conflicts that tend to increase the difficulties of substantive advances towards increasing school justice.

\section{Keywords}

Right to education - Human rights - Just school - Social justice.

\section{Introdução}

Em El impacto de los informes de desarrollo humano del PNUD en Chile, Claudio Ramos Zincke e Eliane Gonzáles (2006) avaliam a repercussão, no mundo acadêmico, dos Relatórios do Desenvolvimento Humano (RDHs) encampados pelo Programa das Nações Unidas para o Desenvolvimento (PNUD). Eles sugerem que documentos dessa natureza têm assumido também o papel de produtores de conhecimento. Recebem inúmeras influências do mundo acadêmico, mas também produzem saberes que são incorporados às pesquisas e investigações cujo intento é diagnosticar problemas nas áreas sociais, políticas, econômicas e educacionais e prescrever ações e procedimentos para solucioná-los ${ }^{3}$.

3 - Muitos cientistas sociais, no limiar do século XXI, fazem referências, em seus estudos, aos RDHs. Entre eles estão: Bauman (2001), Therborn (2001), Furtado (1999, 2002). No ISCTE (Portugal) é possível ter acesso a uma bibliografia sobre desigualdades sociais contemporâneas na qual os RDHs de 2013 e 2014 constam como referências entre dezenas de cientistas que tratam desse tema. A respeito do assunto: https://fenix.iscte-iul. pt/disciplinas/m8065-1/2014-2015/1-semestre/bibliografia. 
Não há dúvida de que não são apenas os RDHs que geram ideias e absorvem conhecimentos produzidos no âmbito acadêmico e fora dele; também o fazem os REPTs (Relatórios de Monitoramento da Educação para Todos) da UNESCO (Organização das Nações Unidas para a Educação, a Ciência e a Cultura) e o fazem em uma espécie de hermenêutica de mão dupla, conforme sugere Giddens (1993), ou seja:

0 fluxo entre as ideias e os conceitos cunhados pelas diversas Ciências Sociais e aqueles veiculados pelos próprios atores leigos ${ }^{4}$, em seus discursos, e/ou por eles recursivamente implementados como conhecimento prático na produção de suas ações, é de mão dupla. (PETERS, 2014, p.181).

De que tratam esses dois blocos de documentos intitulados RDHs e REPTS? Os primeiros (PNUD; RDH, 1990, 2001, 2004) ${ }^{5}$ constituem-se um conjunto de materiais encomendados e publicados, anualmente, desde 1990, pelo PNUD (Programa das Nações Unidas para o Desenvolvimento) com o objetivo de apresentar, aos Estados nacionais e às organizações da sociedade civil, diagnósticos e prognósticos acerca dos avanços e não-avanços dos processos de desenvolvimento humano fundamentado em três eixos básicos: educação, saúde e renda, ou, se não os houve, quais foram as razões de sua nãoocorrência. Já os REPTs, encomendados e encampados pela UNESCO, procuram monitorar as metas denominadas Educação para Todos acordadas entre a Declaração Mundial Educação para Todos (1990) e o acordo intitulado EDUCAÇÃO para Todos - compromisso de Dakar (2000). Tanto os RDHs quanto os REPTs:

[...] são publicações confeccionadas por inúmeras equipes oriundas de organizações, instituições [...] diversas. As posições e posturas divulgadas [por eles] podem ser estudadas sob os mais variados aspectos, desde os debates sobre qualidade educacional, competências, déficit orçamentário e financeiro para a educação, desigualdade de aprendizagem, nutrição e dificuldade de aprendizado, dificuldades de universalização do ensino para meninos e meninas, até as discussões sobre evasão escolar, educação e pobreza, profissão docente, inclusão e exclusão, entre outros. (REZENDE, 2014, p. 19).

Esclarece-se que, do ponto de vista metodológico, a análise documental precisa levar em conta o contexto sócio-histórico (QUEIRÓZ, 2008) no qual os RDHs e os REPTs estão sendo produzidos. "Isto exige que se faça uma articulação entre as narrativas veiculadas nos relatórios e o contexto social [...] gerador delas” (REZENDE, 2015, p. 35). 0 desvendamento dos documentos possibilita trazer a público os seus significados políticos, sociais e ideológicos. No caso dos documentos analisados, neste artigo, é sabido que eles foram selecionados porque têm o potencial de explicitar:

[...] as relações entre múltiplas configurações interdependentes (estados, organismos internacionais, movimentos sociais, partidos políticos, governos, associações profissionais e econômicas, organizações não-governamentais, instituições sociais e políticas). (REZENDE, 2015, p. 35).

\footnotetext{
4- Leigos ou não. Os produtores dos RDHs são oriundos, muitas vezes, das ciências humanas e sociais.

5- Os RDHs de 2001 e de 2004 dedicam-se, com maior ênfase, ao tema da educação.
} 
Busca-se, por meio da análise documental, “compreender e interpretar os enfoques escolhidos, pelos formuladores e encampadores dos relatórios, para registrar dados, informações, diagnósticos, prescrições e propostas" (REZENDE, 2015, p. 36). Tais registros "expressam um conjunto de embates, acordos, desacordos, consensos, dissensos e disputas" (REZENDE, 2015, p. 36) acerca de concepções de justiça, justiça escolar e escola justa.

Todavia, os relatórios também são "uma forma de comunicação acerca dos problemas sociais, no limiar do século XXI, inscrita num certo grau de interação entre os diversos grupos humanos (ELIAS, 1994) que formam a humanidade hoje" (REZENDE, 2015, p. 37). Esclarece-se, então, que não se está buscando apenas uma dada estrutura argumentativa, uma vez que isso poderia levar à pressuposição de que existe uma "autonomia do argumento em relação às complexidades configuracionais" (REZENDE, 2015, p. 38), para usar uma expressão de Norbert Elias (1994).

A análise documental realizada nesta investigação não concebe qualquer autonomia do argumento e da narrativa em relação ao contexto sócio-histórico. Pressupõe, sim, a necessidade de considerar o contexto social e político no qual os registros textuais são produzidos e divulgados no formato de diagnósticos e prognósticos.

Epistemologicamente, acredita-se que a cientificidade da investigação documental exige que, num primeiro plano, se faça uma análise interna do texto para verificação do modo como os argumentos são construídos e, num segundo, estabeleça-se uma correlação entre o texto e o contexto social e político no qual se decide registrar tanto esse ou aquele diagnóstico acerca da escola, da justiça, da educação e das políticas educacionais, quanto essa ou aquela leva de prescrições que os governantes, Estados, organizações internacionais e da sociedade civil devam considerar em suas ações.

0 objeto desta investigação são as prescrições de políticas, sugeridas pelos RDHs e pelos REPTs (UNESCO; REPTS, 2010, 2011, 2012), a serem implementadas tanto no âmbito microssocial quanto no macrossocial, para que se alcancem, de modo crescente e contínuo, os mais pobres e eles, através da escolarização, possam habilitar-se, política e profissionalmente, por meio "da expansão das capacidades educacionais" (ESTEVÃO, 2016, p. 45) a participar de modo cada vez mais equitativo e justo da vida social.

Esse objeto desdobra-se ainda em outro, isto é, as ações, os diagnósticos e os prognósticos acerca das mudanças educacionais sugeridas nos RDHs e nos REPTs e suas aproximações e distanciamentos com alguns elementos dos debates acadêmicos sobre justiça escolar e escola justa. Os documentos foram selecionados levando-se em conta as suas pertinências ao objeto de estudo.

Esses objetos levaram à constituição dos problemas sociológicos expressos nessas questões: Quais são as políticas microssociais e macrossociais, na área educacional, mencionadas pelos formuladores dos RDHs e dos REPTs, como capazes de produzir uma escola mais justa para os segmentos que vivem em situação de pobreza extrema? Quais políticas estão sugeridas nos documentos para habilitá-los e capacitá-los a desfrutarem de uma condição social e política mais inclusiva e democrática? É possivel detectar, nos diagnósticos e prescrições contidos nesses relatórios, aproximações e influências dos debates sociológicos sobre justiça social e justiça escolar? 


\section{Justiça social e justiça escolar: um debate acadêmico e político frutífero para a análise dos RDHs e dos REPTs}

Muitas narrativas acadêmicas sobre justiça escolar, escola justa, justiça social, inclusão, entre outros temas, dialogam, direta ou indiretamente, com os modelos educacionais que têm aparecido, de forma insistente, nos mais variados documentos dos organismos internacionais, nos quais são tratados os temas relacionados ao desenvolvimento econômico, social e político.

Um dos modelos de educação e justiça escolar que mais tem circulado nos debates acadêmicos e nas prescrições de organismos internacionais, como o PNUD, é o modelo das capacidades que Amartya Sen $(2006,2010,2011)$ e Ul Haq $(1978,1995)$ trataram nos $\mathrm{RDHs}^{6}$. Tal modelo das capacidades foi:

[...] rebatizado por Tikly \& Barret (2009), [de] modelo de justiça social [...] e parte da ideia de que haverá necessidade de os direitos se colocarem de uma forma mais decidida ao serviço da expansão das capacidades educacionais. (ESTEVÃO, 2016, p. 43).

Estevão (2002) discorre longamente acerca das diversas noções de justiça e expõe como elas, dependendo da forma pela que são empregadas, repercutem no modo de conceber a escola nas suas mais diversas e complexas relações.

Quando se mencionam os conceitos escola justa e justiça escolar, do que se está falando? É fundamental esclarecer que se podem mencionar essas noções e/ou outras correlatas de modo abstrato, genérico, retórico. Em princípio, todos têm direitos legais à educação. Este é “o modelo da educação como direito, [...] [ele] parte da ideia de que todo ser humano deve [ter], ou tem direito, a uma educação decente, mesmo que [ela] seja economicamente e de forma imediata irrelevante" (ESTEVÃo, 2016, p. 44).

De maneira desavisada, é possível imaginar que, ao pressupor-se que a educação é um direito, considera-se que ela se identifica com uma educação baseada na busca por expansão das capacidades, como apontado por Amartya Sen, o qual tentou se livrar de um entendimento genérico sobre a educação como direito.

Ensinam Dubet $\left(2004 ;\right.$ 2012) e Estevão ${ }^{7}$ (2016) que uma escola justa é aquela que:

[...] consegue explicitar bem o sentido social e cultural da educação e que responde às necessidades e problemas sociais, à melhoria da sociedade, da política, da economia e da cultura, não num sentido errático, mas no sentido emancipatório, dialogado e politizado. (ESTEVÃ0, 2016, p. 53).

[...] a escola não pode deixar de considerar a justiça como direito de todos os alunos a um saber de base, a uma cultura comum, sendo, então, imperioso exigir uma escolaridade mínima

6- Rohling; Valle (2016) sugerem que as pressuposições de John Rawls podem ser tomadas como base para as discussões acerca da justiça escolar e escola justa.

7- Estevão (2016) afirma que esse seu entendimento de escola justa está baseado em François Dubet (2004). 
suficiente para todos, com a mesma efetividade e duração, e equivalente em termos de qualidade. (ESTEVÃO, 2016, p. 53-54).

E, por último, mas não menos importante, diz Estevão:

Uma escola justa e de qualidade deve mobilizar a justiça escolar como igualdade de tratamento, quer no acesso, quer no sucesso, quer na possibilidade de permanecer no sistema, não descurando nunca a promoção ora da justiça como redistribuição (que se prende com a justiça das notas, das avaliações, das orientações, dos apoios) tendo em vista a igualdade entre todos, mas também a justiça diferencialista, dando mais aos que mais necessitam, designadamente aos que revelem dificuldades ou necessidades educativas especiais. Estes terão eventualmente de usufruir de políticas compensatórias, no sentido de os tornar mais capazes de realizar o que de facto valorizam [conforme indica Amartya Sen. (2011)] (ESTEVÃ0, 2016, p. 53-54).

A discussão acerca das razões que podem emperrar os processos de habilitação social e política encontra ressonância também em autores como François Dubet (2012) e Nancy Fraser (2002); que destacam que o debate sobre justiça e desigualdade tem de enfrentar, de modo simultâneo, a necessidade de uma melhor distribuição dos bens materiais e imateriais. Seria, então, frágil qualquer proposição de ampliação da justiça social, justiça escolar sem se considerar a necessidade de distribuição de renda, recursos e poder.

Se não tiverem, em razão da miserabilidade extrema, condições de competir com os demais indivíduos, os mais pobres jamais terão as chamadas capacidades e habilidades para se apresentarem na arena política e sustentarem suas demandas. Conforme assinala Dubet (2012, p. 46), é necessário lutar contra a pobreza e a discriminação que "obstaculizam [até mesmo] a realização do mérito". Com efeito, muito mais complexa é a realização das capacidades e habilidades que vão além da igualdade de oportunidades.

Explica Amartya Sen (1978, 2006, 2010):

[...] o objeto de um processo justo e um acordo justo vai além das vantagens gerais dos indivíduos e abrange outras considerações - em especial, processuais -, que não podem ser adequadamente enfrentadas através da exclusiva concentração nas capacidades. (SEN, 2011, p. 331).

No livro $A$ ideia de justiça, o cientista social indiano procura se livrar inteiramente do entendimento de que sua abordagem é unifocal no que tange à desigualdade. Ou seja, a igualdade de capacidades não basta, em se tratando do combate às múltiplas formas de desigualdades. Veja-se o que Giddens diz sobre isso:

[...] o conceito de 'capacidade social' de Amartya Sen proporciona um ponto de partida apropriado. [...] Políticas formuladas para promover a igualdade devem se concentrar no que Sen [...] chama de 'conjunto de capacidades' - a liberdade geral que a pessoa tem de buscar seu bem-estar. A desvantagem deve ser similarmente definida como a 'falta de capacidade' - não apenas a perda de recursos, mas a perda da liberdade de realizar. A liberdade definida como capacidade social 
não se aproxima do agente interesseiro pressuposto na teoria econômica neoliberal. (GIDDENS, 2007, p. 255).

\section{Os RDHs, os REPTs lidos à luz do debate acadêmico e político sobre justiça social, justiça escolar e escola justa}

Indaga-se: o enquadramento teórico e analítico feito pelos elaboradores dos referidos documentos impede, ou não, entender a escola e suas dificuldades de organizar, de efetivar e de consolidar, nas suas práticas cotidianas, uma interação escolar cada vez mais justa? Tais documentos acabam por abraçar, em tese, a defesa de uma escola justa, uma vez que passam muito distante do entendimento das "lógicas ou racionalidades [que] se confrontam nas decisões quotidianas da escola e estruturam a experiência escolar dos diversos atores educativos" (ESTEVÃ0, 2016, p. 50). Isso se deve, em parte, ao fato de que os relatórios visam a constituir um conjunto extremamente amplo de prescrições para os Estados e para a sociedade civil organizada e não, ao menos de forma direta, para os educadores e administradores escolares.

Amartya Sen $(2010,2011)$ "parte da ideia de que haverá necessidade de os direitos se colocarem de uma forma mais decidida ao serviço da expansão das capacidades educacionais" (ESTEVÃ0, 2016, p.45). Quando se examinam os RDHs e os REPTs se percebe que seus formuladores não vão tão longe quanto Amartya Sen, visto que não lidam com as especificidades de muitos contextos que bloqueiam a efetivação de direitos e impossibilitam que eles sejam, de fato, postos a serviço da expansão das capacidades e habilidades, não só profissionais como também políticas.

Pode-se dizer que os elaboradores desses documentos, que pretendem orientar práticas políticas de governantes e de organizações da sociedade civil, são levados, quase sempre, a fazer uma mescla entre um modelo de educação pautado na exacerbação do elemento cognitivo favorecedor da formação do capital humano e os modelos da educação como direito abstrato e como formador de capacidades. Acredita-se que, ao situar seus diagnósticos e prescrições nesses três modelos ao mesmo tempo, as equipes formuladoras desses relatórios constroem tanto um corpus de estratégias políticas supostamente plausíveis e aceitas socialmente, quanto um corpus ideológico que dificulta entender o quanto esses três modelos se distinguem entre si no que se refere à efetivação de políticas educacionais e escolares e de constituição de demandas nessas duas áreas.

Pode-se perguntar: De que maneira é possível decifrar o modelo de educação aventado nos RDHs e nos REPTS? É realmente possível constatar aproximações e distanciamentos com as pressuposições em torno de uma escola justa e de uma justiça escolar? 0 primeiro passo é comparar seus diagnósticos e prognósticos, na área educacional, com uma noçãochave de escola justa.

Detecta-se que alguns dos elementos referentes à justiça diferencialista, de dar “mais aos que mais necessitam” (ESTEVÃo, 2016, p. 54), estão presentes, de um modo ou de outro, nos relatórios ora analisados. Porém, a prescrição de ações e procedimentos para alcançar os que estão em situação de maiores dificuldades sociais e educacionais aparece 
ajustada - política e ideologicamente - àquilo que se mostra, de alguma forma, exequível num plano mais imediato.

Para os RDHs e os REPTs constitui-se núcleo central o fato de a educação haver-se tornado um meio de melhoria da sociedade não só porque os indivíduos podem conseguir superar, aos poucos, os problemas sociais, mas também porque ela faculta ao estudante dotar-se de qualidades emancipatórias capazes de ampliar consistentemente a sua atuação política na sociedade.

Esses dois documentos tratam de diversos temas que atravessam o debate acadêmico sobre escola justa e justiça escolar. Em razão das muitas questões que cercam essas discussões, Dionísio (2010) examina com atenção questões referentes à eficácia no debate acerca da justiça escolar. Na discussão pública, é recorrente a ideia de que a escola tem de ser eficaz. Observa-se que esse ideário de eficácia acaba por impor, ao modo como se tenta juntar à ideia de eficácia e o ideário de justiça escolar, diversos dilemas, que estão presentes nas práticas sociais dos diversos agentes escolares. Observem-se esses trechos dos relatórios:

Un sistema de educación demuestra su eficacia cuando es capaz de cumplir su objetivo esencial: dotar a los jóvenes con las competencias que necesitan para encontrar medios seguros de subsistencia participar activamente en la vida social, económica y política de sus comunidades. (UNESCO; REPTs, 2011, p. 11).

Las competencias lingüisticas, cognitivas y sociales adquiridas en su primera infancia son las bases para que aprenda durante toda su vida. Si no las adquiere por nutrición insuficiente, falta de estímulos, estrés afectivo u otros factores, esto supone un gran costo, personal y social, y socava la eficacia y equidad del sistema educativo. (UNESCO; REPTs, 2011, p. 33).

Entre as muitas prescrições suscitadas por este debate, cita-se, com frequência, aquela ideia que insiste que a educação tem de preparar os agentes estudantis para que sejam capazes de intervir no mundo cívico e de se arranjar no mundo do trabalho (ESTEVÃ0, 2002, 2016; BOLTANSKI, 1982, 2009; BOLTANSKI; THÉVENOT, 1991; RESENDE; DIONÍSIO, 2005; DIONÍSIO, 2010) ${ }^{8}$.

Manejar esses dois mundos (o cívico e o do trabalho) exige, assim o entendem os formuladores desses relatórios, uma ampliação do processo educacional de modo que todos os indivíduos, incluindo-se os mais pobres, possam estar capacitados profissional e politicamente. Veja-se o que expõem os respectivos documentos: "É evidente a existência de uma correlação entre os programas de alfabetização de adultos e o aumento da participação em atividades sindicais e comunitárias" (UNESCO; REPT, 2006, p. 148). No RDH de 1993 consta que "a participação [é] uma estratégia global de desenvolvimento, centrando-se no papel fundamental que devem desempenhar as pessoas em todas as esferas da vida" (PNUD; RDH, 1993, p. 25).

8- Campos (2016), Celikates (2012) e Correa; Dias (2016) têm reflexões essenciais para a compreensão da perspectiva sociológica de Boltanski; Thévenot $(1991,1999)$. 
Nos documentos ora analisados, há referências constantes à necessidade de tornar a educação um fator, por excelência, de melhoria da sociedade, já que ela deve visar, como meta constante, à solução dos problemas sociais. Tal solução é pensada sempre, no interior desses materiais do PNUD e da UNESCO, tomando-se os indivíduos não apenas como agentes capazes de intervir no mundo cívico e no mundo da subsistência material, mas também como seres aptos a participar da contenda política e da geração de meios de sobrevivência.

Qual é o maior problema desse tipo de entendimento? É serem os indivíduos, como afirma Bauman (2001), encarregados de resolver problemas de grande monta. "Em outras palavras, consiste no estabelecimento de uma autonomia de jure (independentemente de a autonomia de facto também ter sido estabelecida)" (BAUMAN, 2001, p. 41).

Há dois aspectos intrigantes tanto nos diagnósticos e nas prescrições postos nos documentos do PNUD e da UNESCO analisados, quanto nas pressuposições que alimentam o debate sobre justiça escolar e escola justa, a saber, um é a ideia de habilitação política e o outro é a ideia de justiça. Os dois são desafiados pelos ideários, como sistema de ideias e valores, construtores dos documentos e, também, dos movimentos de ideais que norteiam a busca por justiça escolar e por uma escola justa.

Diante das muitas narrativas ambíguas e até mesmo ambivalentes acerca dos vários entendimentos sobre justiça, pode-se indagar: Qual ou quais ideias de justiça balizam os RDHs e os REPTs? Há neles uma linha de raciocínio clara sobre o que os seus formuladores entendem por justiça? Não há. Porém, pode-se dizer que, em muitos momentos, eles permitem entender que a justiça é pensada sem a sofisticação do debate teórico e filosófico levantado por Rawls (1992) e Sen (2011), como sinônimo de equidade.

Não é possível entrar aqui no debate de Sen (2011) com as teses de John Rawls (1992) sobre a justiça como equidade. Os RDHs encontram-se mais próximos da abordagem de Sen que deseja se afastar de "uma visão de justiça focada em arranjos" (SEN, 2011, p. 50) e se aproximar de uma "compreensão de justiça focada em realizações” (SEN, 2011, p. 40). Mas pela própria natureza desses documentos, RDHs e REPTs, nota-se que eles estão empenhados em exaltar as razões públicas que justificam a busca da justiça como equidade (RAWLS, 1992) ou a realização da justiça como capacidade. Nesse aspecto, os elaboradores desses documentos têm interface com os dois pensadores.

Em tais documentos, uma sociedade é mais justa quando os indivíduos, ainda que em situações muito distintas, são dotados de capacidade e habilidades e dispõem de oportunidades mais equitativas. Ou melhor, há mais justiça quando aos indivíduos, ainda que em situação de pobreza extrema e de pertencimento a grupos raciais, étnicos ou religiosos específicos, é facultado alcançar melhorias sociais, educacionais e de participação política.

Há, sobre a abordagem das capacidades e da formação de habilidades, uma reflexão muito frutífera de Celso Furtado (2002) que destoa da perspectiva de Amartya Sen ${ }^{9}$. Em primeiro lugar, para o cientista social brasileiro, existe a necessidade de uma contextualização histórica dos parâmetros estruturais (concentração de poder, de renda, de recursos, de

9- Não se pode supor que os RDHs incorporam, na sua totalidade, a abordagem de Sen acerca das capacidades. 0 próprio autor indiano (SEN, 2010, p. 110) reconhece o uso parcial de sua abordagem pelos produtores dos relatórios. 
patrimônio, de escolarização) causadores dos bloqueios que impedem a expansão tanto da habilitação profissional e política quanto das capacidades para entender e intervir nos funcionamentos (nos valores, normas, regras, representações, percepções, motivação, disposições, expectativas, perspectivas) que poderiam impulsionar a justiça social.

Com relação a países, como o Brasil, e muitos outros, Furtado (2002) alerta para o risco de falar em justiça social sem a superação de muitos bloqueios que vêm impedindo todo e qualquer processo de habilitação profissional e político.

\begin{abstract}
Isso porque, para participar da distribuição da renda, a população necessita estar habilitada por um título de propriedade ou pela inserção qualificada no sistema produtivo. Ora, há sociedades em que esse processo de habilitação está bloqueado. [...] Para que os pobres alcancem a habilitação de que fala Sen $(2010 ; 2006 ; 2011)$, precisam ter acesso a meios que lhes assegurem [...] certa renda. (FURTADO, 2002, p. 16-7).
\end{abstract}

Dialogando com as teses de Amartya Sen e com as prescrições de organismos internacionais influenciados por suas proposições, Celso Furtado acrescentava: "Para que os pobres alcancem a habilitação de que fala Sen, precisam ter acesso a meios que lhes assegurem certa renda" (FURTAD0, 2002, p. 17). E por que o cientista social brasileiro levanta esse tipo de problema? Porque Sen (2008, 2010), em vários momentos, insiste que a inadequação de capacidades pode bloquear até mesmo a expectativa, a perspectiva, a motivação e a disposição dos indivíduos mais pobres para acreditarem na viabilidade, factibilidade e razoabilidade da escolarização de suas crianças.

Celso Furtado considera que esse tipo de posição, ainda que correto, pode levar ao desvio de algo que tem prevalência na organização da vida social: sem diminuir as desigualdades extremas e a pobreza extrema e sem que as pessoas tenham uma renda capaz de possibilitar-lhes sobreviver dentro de padrões minimamente razoáveis, bloqueiase qualquer habilitação profissional ou política. Não há adequação de capacidade se a pessoa está mergulhada na miséria. Todavia, não há como avançar no combate à pobreza e às desigualdades sem investimento no fator humano (FURTAD0, 1999). A educação, neste caso, só é justa se vier a ser algo que permita aos indivíduos participarem, de fato, da contenda no mundo do emprego e da política.

\title{
Capacidades sociais e políticas como elementos norteadores da justiça escolar
}

Os formuladores do REPT de $2010^{10}$, intitulado Chegar aos marginalizados, debatem longamente acerca de como se deve direcionar o gasto público para que a educação dos marginalizados, dos que vivem em pobreza extrema, seja capaz de lhes ampliar as capacidades, até mesmo aquelas voltadas para a obtenção de recursos políticos (UNESCO; REPTs, 2010).

A escola, como espaço de conflitos, ganha expressividade quando se pretende discutir justiça escolar e escola justa. Os diagnósticos e prescrições genéricos, como os

10- Sobre os REPTs de 2010, ver Shishito (2015). 
dos RDHs e dos REPTs, passam geralmente ao largo dos processos conflitivos, que podem dificultar, no contexto escolar, a ampliação da justiça escolar.

Os conflitos na escola são múltiplos e complexos, assim como os da sociedade em que está imersa: instituição cercada de debates sobre o quê, como, para quem ensinar. Quem pode ensinar, quem pode orientar, quem pode coordenar, quem pode dirigir? É uma instituição disputada, com seu sentido sempre questionado. (SCHILLING; ANGELUCCI, 2016, p. 701).

Os diagnósticos e as prescrições dos RDHs e dos REPTs tornam-se genéricos e abstratos demais por estarem falando ao mundo todo e de maneira difusa. A consequência é que não se apreendem as particularidades, de países e regiões, relacionadas aos bloqueios estruturais que impedem a formação de capacidades e habilidades capazes de levar a uma efetiva compreensão dos funcionamentos que comandam a vida social.

Deriva disso um enquadramento analítico - em vista da amplitude desses materiais que prescrevem ações e procedimentos a contextos sociais e políticos muito distintos responsável por fazer pensar a educação, a escola, a justiça social e a liberdade, sem se discutir o cotidiano escolar e as demais cotidianidades que bloqueiam a formação de tais habilitações sociais e políticas.

Não se está supondo que caberia a esse tipo de orientação prescritiva dos RDHs e REPTs chegar às particularidades do cotidiano escolar, mas sim que, se isso não se fizer, a orientação desses documentos nos levará a pensar que a justiça escolar e a justiça social são, por meio da educação, muito mais facilmente realizáveis do que realmente o são.

Ocorre, assim, como diria Norbert Elias (1994, 2001), um processo de ideologização, no qual se confunde o idealizável com o realizável. Há um enquadramento analítico em que a prescrição de uma educação geradora de justiça social, por meio da ampliação das habilidades e capacidades, transforma-se em uma crença inconteste que leva a muitas outras idealizações.

Veja-se o tipo de enquadramento analítico feito pelo RDH de 1997 acerca da pobreza e de sua possível superação:

[0 fenômeno da] pobreza é demasiado complexo para reduzir-se a uma dimensão única da vida humana. [A superação da pobreza está] na possibilidade das pessoas ampliarem suas opções, terem educação e desfrutarem de uma vida longa, sadia e decente. Entre outras opções adicionais se incluem a liberdade política [e] a garantia de outros direitos humanos. (PNUD; RDH, 1997, p.17).

Enquanto os relatórios não enfrentam, a contento, as questões postas a seguir por Therborn (2001), pode-se dizer que muitos acadêmicos que têm problematizado o tema da justiça escolar têm se dedicado a isso:

A desigualdade nas capacidades, ou nas oportunidades de vida [...] podem ser consideradas como uma soma de recursos e ambientes. Ambos são pertinentes à capacidade de conquistar feitos e realizações às quais se tenha motivos para dar valor. Mas, enquanto os recursos podem ser distribuídos individualmente, os ambientes indicam a ausência ou presença de contextos de acesso e de possibilidades de escolha. (THERBORN, 2001, p. 131). 
Contudo, é constatável que os RDHs estão inspirados na abordagem das capacidades feita por Sen, mas, por serem somente uma inspiração, suas prospecções não condizem integralmente com as suas perspectivas; todavia, insistem continuamente que a adequação de capacidades é fator, por excelência, de combate às desigualdades, já que ela leva à melhoria da renda, da nutrição, da escolarização.

Sen (2008) faz distinção entre igualdade de oportunidades e igualdade de capacidades, distinção que os formuladores dos documentos do PNUD e da UNESCO, aqui trabalhados, não fazem suficientemente. Muitas vezes, essas duas noções parecem semelhantes e com poucos elementos distintivos. Ensina Sen (2008, p. 37): “o modo mais adequado de apreciar a igualdade real de oportunidades deve ser por intermédio da igualdade de capacidades”.

Aos RDHs e REPTs, que apostam numa maior igualdade de oportunidades por meio da educação como solução para os diversos problemas ligados às desigualdades, cabe dizer que esse tipo de igualdade (a de oportunidades): "não diz nada das distâncias que separam as condições sociais, [as quais] podem ser tão grandes que os indivíduos não [conseguem] atravessá-las nunca, com exceção de alguns heróis [...]” (DUBET, 2012, p. 49). Na verdade, os documentos internacionais, aqui tratados e que se dedicam ao tema da educação, constroem muitas estratégias, para evitar tratar das longas distâncias sociais e se fixam em distâncias de muito menor alcance dentro dos mesmos grupos.

Os agricultores da república da Coreia, Malásia e Tailândia, utilizando a tecnologia moderna, produziram 3\% mais por cada ano adicional de educação recebida. E o maior nível de educação dos agricultores do Punjab hindu explica, em parte, porque sua produtividade é maior que a dos agricultores do Punjab paquistanês. (PNUD; RDH, 1990, p. 68).

Assinale-se que, na América Latina, há muitos estudiosos (ZICCARDI, 2002; CORAGGIO, 1998; QUINTI, 1997) dedicados a temas que dialogam com as problemáticas levantadas pela literatura sobre justiça escolar e escola justa. Também esses estudiosos buscam entender, entre outras coisas, até que ponto a escolarização, caso conseguisse tornar-se sempre mais inclusiva, teria a possibilidade de combater a pobreza, a miserabilidade, no continente.

Uma distribuição mais equitativa de conhecimento, de habilidade, de capacidade diminuiria, de fato, as exclusões, a penúria, a privação e a sensação de impotência? Gabriele Quinti (1997, p. 74) responde afırmativamente, pois a pobreza extrema somada à falta de escolarização estaria na base da "exclusão social direta". Note-se que, em uma hermenêutica de mão dupla (PETERS, 2014), esses debates aparecem fortemente nos REPTs.

\footnotetext{
Muitas das medidas necessárias para superar a marginalização na educação se situam no ponto de intersecção entre a política de educação e as estratégias de reformas mais vastas. A redistribuição do gasto público é um dos elementos essenciais para tornar extensivos os direitos e ampliar a oferta de oportunidades. Como a marginalização na educação está unida à pobreza, as regiões mais pobres frequentemente são as que têm menos capacidade para mobilizar recursos. (UNESCO; REPT, 2010, p. 14).
} 
Atenção e educação da primeira infância, no caso do Brasil considera-se que a expansão da escolarização primária (o que melhorou a educação das mães), os serviços de saúde materno-infantil e, em menor medida, a melhoria dos sistemas de abastecimento de água e saneamento são as principais razões que explicam este resultado impressionante, somadas ao crescimento equitativo. (UNESC0; REPT, 2012, p. 52).

Entre as inúmeras críticas que recaem sobre esses materiais estão aquelas que dizem que tais documentos se dedicam mais a pensar a marginalização educacional e menos a marginalização sistêmica.

\section{Considerações finais}

Por fim, pode-se dizer que a natureza política e prescritiva dos RDHs e dos REPTs, tende a fazer crer que realizar a justiça é o mesmo que capacitar e dar oportunidade. Para Sakiko Fukuda-Parr (2002), que atuou como diretora dos RDHs, a abordagem das capacidades de Sen funciona como uma espécie de moldura conceitual para os documentos. Isso quer dizer que os formuladores dos documentos do PNUD não utilizam, de modo integral, a perspectiva de Amartya Sen, mas operam, de certo modo, com suas ideias acerca da noção de pobreza, de capacidades e de funcionamentos.

A sociedade, como um todo, e a escolarização, em particular, tornam-se mais justas se ocorrem processos, não esporádicos nem erráticos, de compreensão dos funcionamentos da vida social. Por funcionamentos, conforme já assinalava Durkheim ${ }^{11}$ (1984), entendem-se valores, regras, normas, representações coletivas. Nesse caso, a justiça (social e escolar) realiza-se somente se os indivíduos (em todas as esferas da vida social - exalta-se aqui a esfera escolar) aderirem a "universos de justiça" (RESENDE; DIONÍSIO, 2005, p. 678) amplamente compartilhados.

Muitas vezes, a educação para a cidadania é tida como sinônimo de uma escolarização capaz de levar os agentes estudantis a entenderem os funcionamentos que podem tornar uma sociedade mais justa, mais igualitária. Isso os faria ter, supostamente, uma maior participação social e política.

Faz, assim, todo o sentido falar de 'político' se com isso se entende a forma como se produzem acordos sobre 'valores partilhados' ao exprimirem-se, nas experiências estudantis, denúncias e críticas permanentes, que manifestam, verdadeiramente, adesões a universos de justiça. (RESENDE; DIONÍSIO, 2005, p. 678).

É evidente que análises dessa magnitude pressupõem uma leitura rigorosa dos contextos sociais dos quais se está falando ${ }^{12}$. Em quais contextos sociais e escolares parece plausível uma formação cidadã voltada para um entendimento cada vez melhor da necessidade de construir relações mais justas em todos os âmbitos sociais?

11- Acerca dos funcionamentos sociais, tanto Sen quanto Durkheim foram influenciados por Adam Smith (1999).

12- Flávia Schilling e Carla Angelucci (2016) estudam o contexto escolar para verificar, no seu interior, e entre os seus agentes, as (im) possibilidades de constituição de uma escola mais justa. 
Aos RDHs e aos REPTs escapam, muitas vezes, as particularidades que desafiam os seus diagnósticos e prescrições. Eles parecem, em muitos momentos, interessados em assinalar, de modo geral, que a "desigualdade social em educação" (UNESCO; REPT, 2009, p. 153) deve ser combatida por meio de uma melhor distribuição de recursos e/ou de "uma reorientação dos fundos públicos” (PNUD; RDH, 2001, p. 86).

Não foi possível, no âmbito dessa discussão, analisar os muitos intentos dessas duas organizações internacionais para impulsionar os muitos modelos de educação, de práticas pedagógicas e de escolarização, que sejam supostamente capazes de fomentar melhorias individuais e coletivas. Foram analisadas somente algumas prescrições presentes nos RDHs e nos REPTs que indicam a necessidade de combater as muitas desigualdades educacionais.

Pode-se perguntar: por que têm relevância, nesta discussão sobre justiça social, escola justa e justiça escolar, posições encampadas pelos organismos ligados às Nações Unidas, tais como o PNUD e a UNESCO? Stephen Castles (2002) diz que estudar as transformações sociais, hoje, ou as possibilidades de que elas ocorram passa pelo entendimento das ações e dos procedimentos das organizações intergovernamentais (entre muitas outras estão as Nações Unidas e suas agências ${ }^{13}$, $\operatorname{programas}^{14}$, fundos ${ }^{15}$, comissões técnicas ${ }^{16}$, comissões regionais ${ }^{17}$ ).

Segundo Castles, deve-se atentar para o modo como os organismos internacionais estão lidando, na atualidade, com as possibilidades concretas e/ou idealizadas (pelas Ciências Sociais e/ou pelas organizações da sociedade civil) de mudanças sociais. Faz parte dessa lida um amplo processo de construção, por parte dos organismos internacionais, de enquadramentos teóricos e analíticos acerca de diversos temas, questões e debates (CASTLES, 2002). Entre os temas mais lapidados, em busca desse enquadramento teórico e analítico, estão: educação, desenvolvimento, participação, democracia (CASTLES, 2002).

Os enquadramentos analíticos e teóricos ancorados em soluções que articulam uma multiplicidade de atores, nos denominados processos de governança (WAHL, 2010), tão fortemente aventados pelo PNUD e pela UNESCO, esbarram, nos contextos específicos de cada país, Estado e região, nas formas de concentração de poder, riqueza e recursos (escolarização, meios de participação política e intervenção no debate público). Tais singularidades devem ser consideradas nos processos geradores dos muitos óbices para os avanços da justiça social e escolar.

Se o deficit democrático é brutal, bem como o são também os desequilíbrios de poder, nos âmbitos institucionais (em inúmeros países), quais são as possibilidades de constituir ações e procedimentos permanentes de busca por justiça social, por justiça escolar e por escolas cada vez mais justas? A resposta a esse tipo de indagação demanda muitas outras investigações.

\footnotetext{
13 - A UNESCO é uma agência especializada ligada ao Conselho Econômico e Social das Nações Unidas.

14- $O$ PNUD é um programa também ligado ao Conselho Econômico e Social das Nações Unidas.

15- UNFPA (Fundo de Populações das Nações Unidas) é um exemplo deste tipo de organização.

16- Tais como a de Desenvolvimento Social, a de Desenvolvimento Sustentável, Status da Mulher, entre outras. Elas estão ligadas ao Econômico e Social das Nações Unidas.

17- A CEPAL (Comissão Econômica para América Latina é uma dessas comissões regionais) da ONU.
} 


\section{Referências}

BAUMAN, Zygmunt. Modernidade líquida. Rio de Janeiro: Jorge Zahar, 2001.

BOLTANSKI, Luc. De la crítique: precis de sociologie de l' émancipation. Paris: Gallimard, 2009.

BOLTANSKI, Luc. Les cadres: la formation d' un groupe social. Paris: De Minut, 1982.

BOLTANSKI, LUC; THÉVENOT, Laurent. De la justification: les économies de la grandeur. Paris: Gallimard, 1991.

BOLTANSKI, LUC; THÉVENOT, Laurent. The sociology of critical capacity. European Journal of Social Theory, London, v. 2, n. 3, p. 359-377, 1999. Disponível em: https://journals.sagepub.com/ doi/10.1177/136843199002003010. Acesso em: 14 dez. 2020.

CAMPOS, Luiz Augusto. Qual capacidade crítica? Relendo Luc Boltanski à luz de Margaret Archer. Revista Sociedade e Estado, Brasília, DF, v. 31, n. 3, p. 719-740, set./dez. 2016. Disponível em: https://periodicos. unb.br/index.php/sociedade/article/view/6169/5497. Acesso em: 14 dez. 2020.

CASTLES, Stephen. Estudar as transformações sociais. Sociologia, Problemas e Práticas, Oeiras, n. 40, p. 1-16, set. 2002. Disponível em: http://www.scielo.mec.pt/pdf/spp/n40/n40a07.pdf. Acesso em: 13 dez. 2020.

CELIKATES, Robin. "0 não reconhecimento sistemático e a prática da crítica". Novos Estudos Cebrap, São Paulo, n. 93, p. 29-42, 2012. Disponível em: http://www.scielo.br/scielo.php?pid=S0101$33002012000200004 \&$ script=sci. Acesso em: 20 nov. 2020.

CORAGGI0, José Luis. Sobre la investigación y su relación con los paradigmas educativos. In: WARDE, Mirian Jorge (org.). Novas políticas educacionais: críticas e perspectivas. São Paulo: PUCSP: PEPGE, 1998. p. 73-84.

CORREA, Diogo S.; DIAS, Rodrigo Castro. A crítica e os momentos críticos: de la justification e a guinada pragmática na Sociologia francesa. Mana, Rio de Janeiro, v. 22, p. 1-19, abr. 2016. Disponível em: https:// www.scielo.br/pdf/mana/v22n1/1678-4944-mana-22-01-00067.pdf. Acesso em: 12 dez. 2020.

DECLARAÇÃO MUNDIAL SOBRE EDUCAÇÃO PARA TODOS. Jomtien: [s. n.], 1990. Disponível em: http:// www.direitoshumanos.usp.br/index.php/Direito-a-Educa\%C3\%A7\%C3\%A3o/declaracao-mundial-sobreeducacao-para-todos.html. Acesso em: 13 dez. 2020.

DIONÍSIO, Bruno. 0 paradigma da escola eficaz entre a crítica e a apropriação social. Sociologia, Porto, v. 20, p. 305-316, 2010. Disponível em: https://www.redalyc.org/pdf/4265/426539981016.pdf. Acesso em: 12 dez. 2020.

DUBET, François. Los límites de la igualdad de oportunidades. Nueva Sociedad, Buenos Aires, n. 239, p. 42-50, mayo/jun. 2012. Disponível em: https://nuso.org/media/articles/downloads/42_1.pdf. Acesso em: 12 dez. 2020. 
DUBET, François. 0 que é uma escola justa? Cadernos de Pesquisa, São Paulo, v. 34, n. 123, p. 539-555, set./dez. 2004. Disponível em: http://www.scielo.br/pdf/cp/v34n123/a02v34123.pdf. Acesso em: 20 nov. 2020.

DURKHEIM, Emile. A divisão do trabalho social. Lisboa: Presença, 1984.

EDUCAÇÃO para Todos: o compromisso de Dakar. Daka: [s. n.], 2000. Texto adotado pelo Fórum Mundial de Educação, Dakar, Senegal, 26 a 28/04/2000. Disponível em: http://www.direitoshumanos.usp.br/index. php/Direito-a Educa\%C3\%A7\%C3\%A30/declaracao-de-dakar.html. Acesso em: 12 dez. 2020.

ELIAS, Norbert. A sociedade dos indivíduos. Rio de Janeiro: Jorge Zahar, 1994.

ELIAS, Norbert. Norbert Elias por ele mesmo. Rio de Janeiro: Jorge Zahar, 2001.

ESTEVÃO, Carlos V. Justiça complexa e educação: uma reflexão sobre a dialectologia da justiça em educação. Revista Crítica de Ciências Sociais, Lisboa, n. 64, p. 107-134, 2002. Disponível em: https:// www.ces.uc.pt/publicacoes/rccs/artigos/64/RCCS64-107-134-Carlos\%20Estevao.pdf. Acesso em: 14 dez. 2020.

ESTEVÃO, Carlos V. Justiça social e modelos de educação: para uma escola justa e de qualidade. Revista Diálogo Educacional, Curitiba, v. 16, n. 47, p. 37-58, jan./abr. 2016. Disponível em: https://periodicos. pucpr.br/index.php/dialogoeducacional/article/view/1903 Acesso em: 14 dez. 2020.

FRASER, Nancy. A justiça social na globalização: redistribuição, reconhecimento e participação. Revista Crítica de Ciências Sociais, Lisboa, n. 63, p. 7-20, out. 2002. Disponível em: https://www.ces.uc.pt/ publicacoes/rccs/artigos/63/RCCS63-Nancy\%20Fraser-007-020.pdf. Acesso em: 12 dez. 2020.

FUKUDA-PARR, Sakiko. Operacionalizando as ideias de Amartya Sen sobre capacidades, desenvolvimento, liberdade e direitos humanos: 0 deslocamento do foco das políticas de abordagem do desenvolvimento humano. [S. I.: s. n.], 2002. Disponível em: http://sergiorosendo.pbworks.com/f/ Fukuda-Parr+2002+Sen.pdf. Acesso em: 14 dez. 2020.

FURTAD0, Celso. A reconstrução do Brasil. Praga, São Paulo, n. 8, p. 9-13, ago. 1999.

FURTAD0, Celso. Em busca de novo modelo. Rio de Janeiro: Paz e Terra, 2002.

GIDDENS, Anthony. A questão da desigualdade. In: GIDDENS, Anthony. 0 debate global sobre a terceira via. São Paulo: Unesp, 2007. p. 253-267.

GIDDENS, Anthony. New rules of sociological method. London: Polity Press, 1993.

PETERS, Gabriel. Anthony Giddens entre a hermenêutica e a crítica: o status do conhecimento de senso comum na teoria da estruturação. Plural, São Paulo, v. 21, n. 2, p. 168-194, 2014.

PNUD; RDH. Informe del desarrollo humano: definición y medición del desarrollo humano. Bogotá: Tercer Mundo, 1990. Disponível em: http://desarrollohumano.org.gt/wp-content/uploads/2016/04/HDR-1990. pdf. Acesso em: 12 dez. 2020. 
PNUD; RDH. Informe del desarrollo humano: desarrollo humano para erradicar la pobreza. Madrid, Mundi-Prensa, 1997. Disponível em: https://derechoalaconsulta.files.wordpress.com/2012/02/pnudinforme-1997-versic3b3n-integral.pdf. Acesso em: 12 dez. 2020.

PNUD; RDH. Informe del desarrollo humano: participación popular. Madrid: Cldeal, 1993. Disponível em: http://hdr.undp.org/sites/default/files/hdr_1993_es_completo_nostats.pdf. Acesso em: 14 dez. 2020.

PNUD; RDH. Informe del desarrollo humano: poner el adelanto tecnológico al servicio del desarrollo humano. Madri: Mundi-Prensa, 2001. Disponível em: http://hdr.undp.org/sites/default/files/hdr_2001_ es.pdf. Acesso em: 12 dez. 2020.

PNUD; RDH. Relatório do desenvolvimento humano: a liberdade cultural no mundo hoje. Lisboa: Mensagem, 2004. Disponível em: https://www.br.undp.org/content/brazil/pt/home/library/idh/relatoriosde-desenvolvimento-humano/relatorio-do-desenvolvimento-humano-20004/. Acesso em: 13 dez. 2020.

QUEIROZ, Maria Isaura Pereira. Análise de documentos em ciências sociais. In: LUCENA, Célia Tolentno et al. (org.). Pesquisa em ciências sociais. São Paulo, CERU/USP, 2008. p. 119-145.

QUINTI, Gabriele. Exclusión social: sobre medición y sobre evaluación: algunos modelos. In: LARÍN MÉNJIVAR, Rafael; KRUIJT, Dirk; TIJSSEN, Lieteke Van (coord.). Pobreza, exclusión y política social. Costa Rica: Flacso, 1997. p. 71-93.

RAWLS, John. Justiça como equidade: uma concepção política, não metafísica. Lua Nova, São Paulo, n. 25, p. 25-59, abr. 1992. Disponível em: https://www.scielo.br/scielo.php?script=sci_arttext\&pid =S0102-64451992000100003. Acesso em: 10 dez. 2020.

RESENDE, José Manule; DIONÍSIO, Bruno. Escola pública como "arena" política: contexto e ambivalências da socialização política escolar. Análise Social, Lisboa, v. 11, n. 176, p. 661-680, 2005.

REZENDE, Maria José de. Os relatórios da UNESCO de monitoramento das metas denominadas educação para todos (rept) e os destaques dados às ações do governo brasileiro. Revista Brasileira de Sociologia, Brasília, DF, v. 02, n. 03, p. 17-37, 2014. Disponível em: http://www.sbsociologia.com.br/rbsociologia/ index.php/rbs/article/view/88. Acesso em: 13 dez. 2020.

REZENDE, Maria José de. Uma abordagem histórico-hermenêutica dos relatórios do desenvolvimento humano (PNUD/ONU). E-I@tina, Buenos Aires, v. 13, n. 51, p. 32-51, 2015. Disponível em: https://www. redalyc.org/pdf/4964/496450648003.pdf. Acesso em: 14 dez. 2020.

ROHLING, Marcos; RIBEIRO VALLE, Ione. Princípios de justiça e justiça escolar: a educação multicultural e a equidade. Cadernos de Pesquisa, São Paulo, v. 46, n. 160, p. 386-409, abr./jun. 2016. Disponível em: https://www.scielo.br/pdf/cp/v46n160/1980-5314-cp-46-160-00386.pdf. Acesso em: 12 dez. 2020.

SCHILLING, Flávia; ANGELUCCI, Carla Biancha. Conflitos, violências, injustiças na escola? Caminhos possíveis para uma escola justa. Cadernos de Pesquisa, São Paulo, v. 46, n. 161, p. 694-715, jul./set. 2016. Disponível em: https://www.scielo.br/scielo.php?pid=S0100-15742016000300694\&script=sci_ abstract\&tlng=pt. Acesso em: 14 dez. 2020. 
SEN, Amartya. A desigualdade reexaminada. Rio de Janeiro: Record, 2008.

SEN, Amartya. A ideia de justiça. São Paulo: Cia da Letras, 2011.

SEN, Amartya. Desenvolvimento como liberdade. São Paulo: Cia das Letras, 2010.

SEN, Amartya. El valor de la democracia. Madrid: El Viejo Topo, 2006.

SEN, Amartya. Three notes on the concept of poverty. ILO Working Paper, Gèneve, n. 54, p. 2-23, 1978.

SHISHITO, Fábio Akira. Oportunidades e marginalização educacional: a visão do relatório Educação para Todos de 2010. In: SOUZA LIMA, Angela Maria. Políticas e práticas educacionais. Londrina: UEL, 2015. p. 40-52.

SMITH, Adam. Teoria dos sentimentos morais. São Paulo: Martins Fontes, 1999.

THERBORN, Goran. Globalização e desigualdade: questões de conceituação e esclarecimento. Sociologias, Porto Alegre, v. 3, n. 6, p. 122-169, jul./dez. 2001. Disponível em: https://www.scielo.br/pdf/soc/n6/a07n6. pdf. Acesso em: 12 dez. 2020.

TIKLY, Leon P.; BARRETT, Angeline M. Social justice, capabilities and the quality of education: low income countries. International Journal of Educational Development, Orlando, v. 31, n. 1, p. 3-14, 2011.

UL HAQ, Mahbub. A cortina da pobreza: opções para o terceiro mundo. São Paulo: Nacional, 1978.

UL HAQ, Mahbub. Reflections on human development. New York: Oxford University Press, 1995.

UNESCO; REPTS. La alfabetización, un factor vital: informe de seguimiento de la EPT en el mundo. Paris: United Nations Educational, Scientific and Cultural Organization, 2006. Disponível em: https://unesdoc. unesco.org/ark:/48223/pf0000147000. Acesso em: 24 nov. 2020.

UNESCO; REPTS. Llegar a los marginados: informe de seguimiento de la EPT en el mundo. Paris: United Nations Educational, Scientific and Cultural Organization, 2010. Disponível em: https://unesdoc.unesco. org/ark:/48223/pf0000187865. Acesso em: 13 dez. 2020.

UNESCO; REPTS. Los jóvenes y las competencias: trabajar con la educación: las cuestiones de género: informe de seguimiento de la EPT en el mundo. Paris: United Nations Educational, Scientific and Cultural Organization, 2012. Disponível em: https://unesdoc.unesco.org/ark:/48223/pf0000218569_spa. Acesso em: 13 dez.2020.

UNESCO; REPTS. Superar la desigualdad: por qué es importante la gobernanza: informe de seguimiento de la EPT en el mundo, 2009. Paris: United Nations Educational, Scientific and Cultural Organization, 2009. Disponível em: https://unesdoc.unesco.org/ark:/48223/pf0000183289. Acesso em: 12 dez. 2020.

UNESCO; REPTS. Una crisis encubierta: conflictos armados y educación; informe de seguimiento de la EPT en el mundo. Paris: United Nations Educational, Scientific and Cultural Organization, 2011. Disponível em: https://unesdoc.unesco.org/ark:/48223/pf0000192155. Acesso em: 20 nov. 2020. 
WAHL, Peter. As múltiplas crises e o fracasso da governança global. In: DOWBOR, Ladislau; LOPES, Carlos; SACHS, Ignacy (org.) Riscos e oportunidades em tempos de mudança. São Paulo: Instituto Paulo Freyre; Fortaleza: Banco do Nordeste, 2010. p. 55-67.

ZICCARDI, Alícia. Las ciudades y la cuestión social. In: ZICCARDI, Alícia. Pobreza, desigualdad social y ciudadanía. Buenos Aires: Clacso, 2002. p. 85-126.

ZINCKE, Cláudio R.; GONZÁLES, Elaine. El impacto de los informes de desarrollo humano del PNUD en chile. Santiago de Chile: Universidad Alberto Hurtado, 2006. Disponível em: http://sociologia.uahurtado.cl/ wp-content/uploads/2012/01/C.Ramos_IMPACTO_PNUD_EN_CHILE.pdf. Acesso em: 18 mar. 2019.

Recebido em: 24.05.2020.

Revisado em: 20.10.2020.

Aprovado em: 09.12.2020.

Maria José de Rezende é doutora em sociologia pela Universidade de São Paulo (USP); Professora de sociologia na Universidade Estadual de Londrina (UEL). 